\title{
PREDICTIVE MODELS FOR NORMALIZED SHEAR MODULUS AND DAMPING RATIO OF MODELED ROCKFILL MATERIALS
}

\author{
Ata AGHAEI ARAEI ${ }^{1}{ }^{*}$ and Ahmadreza GHODRATI ${ }^{2)}$ \\ ${ }^{1)}$ Head of Geotechnical Department, Road, Housing and Urban Development Research Center (BHRC), Tehran, Iran \\ ${ }^{2)}$ Institute of Building and Housing, Road, Housing and Urban Development Research Center (BHRC), Tehran, Iran \\ *Corresponding author's e-mail: a.aghaeiaraei@gmail.com
}

\begin{tabular}{l} 
ARTICLE INFO \\
\hline Article history: \\
Received 7 March 2016 \\
Accepted 18 July 2016 \\
Available online 23 August 2016
\end{tabular}

Keywords:

Normalized shear modulus

Damping ratio

Hyperbolic model

Nonlinear multiple regression model

Rockfill material

\begin{abstract}
This study presents predictive models for estimating normalized shear modulus and damping ratio of three compacted remodeled rockfill materials using modified hyperbolic and nonlinear multiple regression methods. The predictive models uses the results of dynamic triaxial tests carried out on cylindrical samples. Tested materials were obtained from the locations of a number of Concrete Faced Rockfill Dams (CFRDs) constructed in Iran. The laboratory test results show that the shear modulus and especially the damping behavior, are influenced by the frequency of loading. The loading frequency and confining pressure were the most important factors that affect dynamic properties of the rockfill materials. In the preliminary part of this paper, the modified hyperbolic method has been considered for developing the predictive models. The predictions did not have enough precision. There were limitations while selecting $\gamma_{r}$, the reference shear strain at $G / G_{O}=0.5$, due to the loading frequency and confining pressure effects. Therefore, results were presented using nonlinear multiple regression approach. The comparison of results shows that the nonlinear multiple regression method is very effective in modeling dynamic properties of soils such as the shear modulus and damping ratio than the classical hyperbolic models.
\end{abstract}

\section{INTRODUCTION}

A number of rockfill dams and Concrete Faced Rockfill Dams (CFRDs) have been constructed in near faults regions which are vulnerable to earthquakes. Therefore, the seismic design of these dams at these earthquake prone regions has become an important issue. The normalized modulus degradation $\left(G / G_{O}\right)$ and damping ratio $(D)$ increase from small to large shear strains $(\gamma)$ are both the key parameters to the fundamental understanding of soil behavior. Soil stiffness is represented by shear modulus and usually expressed in normalized form (divided by the small strain shear modulus, $G_{0}$ ). The $G / G_{0}$ curve is normally used to explain the shear stiffness for a wide range of shear strain. The damping ratio $(D)$ represents the energy dissipated by the soil. Mechanisms that contribute to material damping are friction between soil particles, strain rate effect, and nonlinear soil behavior (Zhang et al., 2005). In past, investigators have used cyclic triaxial or resonant column tests to determine the factors that affect normalized shear modulus and damping ratio for various materials, namely, gravels (Seed et al., 1986; Rollins et al., 1998; Aghaei Araei et al., 2010, 2011a, b, 2012 a, b, c), sands (Wilson, 1988; Kokusho, 1980), loess (Hardcastle and Sharma, 1998) and clays (Idriss et al., 1978; Kokusho et al., 1982, Vucetic and Dobry, 1991; Teachavorasinskun. 2001). Based on the literature review, following factors namely mineralogical composition, dry density, grain size distribution, drainage conditions, moisture content, confining pressure, stress induced isotropy, strength, size and shape of particles, loading frequency and wave forms are identified as important parameters. Further, shear strain $(\gamma)$, effective confining pressure $\left(\sigma_{3}^{\prime}\right)$ and loading frequency are considered as the most important factors that affect the dynamic properties of gravelly soils (Aghaei Araei et al., 2012a).

The variation of shear modulus and damping with shear strain level, $G / G_{0^{-}} \gamma$ and $D-\gamma$ curves, are used as fundamental input parameters in computer programs (Schnabel et al., 1972; Idriss et al., 1973 and Hudson et al., 1994), and numerical analysis for soil modeling and many other seismic response analysis studies. For example, it is a common practice to adopt the upper and lower bounds of the $G / G_{0^{-}} \gamma$ and $D$ $\gamma$ curves proposed by Seed and Idriss (1970), Seed et al. (1986) or Rollins et al. (1998) for granular soils. The similar curves presented by Sun et al. (1988), Vucetic and Dobry (1991) or Stokoe et al. (2004) are also used for soils with variable plasticity index. Alternatively, equations of empirical or analytical models are often utilized. In these models the normalized shear modulus and the damping ratio are commonly expressed as a function of the shear strain amplitude, $\gamma$, the mean effective confining pressure, $\sigma_{m}^{\prime}$, and plasticity index, $P I$.

Seed and Idriss (1970) published the first database of shear modulus degradation curves for sands. The S-shaped curves were obtained from 75 tests of a total of 30 sands, with a wide range of 
confining pressure, relative density and void ratio. Hardin and Drnevich (1972a) and Hardin and Drnevich (1972b) proposed two of the most widely used models (i.e. hyperbolic model) in numerical analyses. Later Darendeli (1997), Darendeli (2001) and Anderson (1974) have suggested the modified hyperbolic model.

Khouri (1984), Aggur and Zhang (2006) and Okur and Ansal (2007) determined damping behavior of granular and cohesive soils for a given shear strain level from the corresponding $G / G_{O}$ ratio using first or second order polynomial relationships alternatively exponential expressions.

Darendeli (2001) presented a more sophisticated model in a modified form where the soil is assumed to exhibit mass behavior. The fitting parameters were determined from experimental data on intact soils of variable plasticity index. Later, Meng (2003) verified his model for granular soils.

Zhang et al. (2005) presented predictive equations for estimating normalized shear modulus and damping ratio of sands and clays. Their equations are also based on a modified hyperbolic model, which includes some variables namely shear strain amplitude, confining pressure, and plasticity index $(P I)$. The damping ratio is also expressed in terms of a polynomial function of normalized shear modulus and minimum damping ratio. Comparisons between these predictive equations and the earlier published expressions shows that the effect of confining stress is more significant, while the effect of $P I$ is less significant in modeling dynamic soil behavior.

Vardanega et al. (2013) presented the analysis of semi empirical expressions for $G_{\max }$ in a simple expression form that uses only a void-ratio function and a confining-stress function. They complied a database of 67 tests on 21 clays and silts using results of undrained shear stress-strain tests on finegrained soils.

Other methods have also been used to predict the $\mathrm{G}$ and $\mathrm{D}$ of soils. Jafarian et al. (2014) used a new aspect of modeling called artificial neural network. In their study, a radial basis function (RBF) neural network model was developed to predict the normalized shear modulus of cohesive soils. Akbulut et al. (2004) also used a neuro-fuzzy network to model the shear modulus and damping ratio behavior of sand. Three predictive systems, adaptive neuro-fuzzy inference system (ANFIS), multi-layer perceptron (MLP) and multiple regression analysis method (MRM) were trained to predict the maximum shear modulus and the minimum damping coefficient.

There is not much research in the literature about the effects of frequency on the behavior of gravelly materials via large triaxial tests. The less information even available on high confining pressures (Aghaei Araei 2012a). Consequently, predictive models have not been developed to estimate shear modulus and damping ratio for the above conditions. Extensive triaxial testing by Aghaei Araei et al. (2011a, 2011b and 2012a) on gravels (e.g. frequency and confining pressure change from 0.1 to $10 \mathrm{~Hz}$ and 100 to
$1500 \mathrm{kPa}$, respectively) revealed that, the shear modulus and especially the damping ratio behavior are influenced by the frequency of loading. Increase in loading frequency increases shear modulus at low strain, but the effect of frequency decreases as strain increases. The damping ratio increases considerably by increasing the loading frequency. The shear modulus increased remarkably by increasing the confining pressure but the damping ratio negligibly changes.

However, none of the suggested models on literature reflect the relationship between the loading frequency and the shear modulus and damping behavior of gravelly soils. In this study, first, a modified hyperbolic model has been used to estimate the shear modulus and damping behavior of high compacted modeled rockfill materials. Despite efforts made in appropriate coefficients selection, the predictions results did not have enough accuracy. Moreover, there are problems and limitations while selecting parameter $\gamma_{r}$ because of loading frequency and confining pressure effects. In other words, in some cases, especially at high confining pressure and high loading frequency, the ratio $G / G_{0}=0.5$ couldn't be reached and parameter $\gamma_{r}$ has been determined by an engineering judgment. Therefore, a different approach namely, nonlinear multiple regression method has been evaluated in predicting the shear modulus and damping ratio of gravelly materials on various shear strain levels. Based on the triaxial test results on gravelly material, the confining pressure, loading frequency and shear strain are considered as the most important parameters that affect the shear modulus and damping ratio.

The proposed $D-\gamma$ and $G / G_{0^{-}} \gamma$ equations in this paper can be utilized in SHAKE family computer programs. They can also be used in numerical analysis for modeling soil behavior or other seismic response analysis. The presented data and equations can be very helpful along with other studies (carried out on coarse grain materials e.g. Seed et al. (1986) and Rollins et al. (1998)), with a special focus on the effects of the loading frequency and high confining pressure.

\section{MATERIAL AND METHODS}

In this study, the data obtained from tested gravelly samples. The materials were prepared from three shell of the under construction Upper and Lower Siah-Bisheh High CFRDs in Iran. Herein these materials are named S.SBU, S.SBLII and S.SBLIV, respectively. The S.SBU were produced by quarry blasting and used in shell materials of the Upper SiahBisheh CFRD. The S.SBLII (from quarry No.II) and the S.SBLIV (from quarry No.IV) materials were also produced by quarry blasting and used for the Lower Siah-Bisheh CFRD. Individual particles are composed of "lime and volcanic rocks" and "lime rock", respectively. The gradation curves of the materials for triaxial testing were obtained with the maximum particle size of $50 \mathrm{~mm}$ (1/6 diameter of large-scale triaxial specimen, $30 \mathrm{~cm}$ ). All materials have the same gradation. $D_{10}, D_{30}, D_{50}$ and $D_{85}$ values are $0.5,2.5$, 
Table 1 Characteristics of materials used in cyclic triaxial tests.

\begin{tabular}{|c|c|c|c|}
\hline Material symbol & S.SBU & S.SBLII & S.SBLIV \\
\hline Maximum particle size $(\mathrm{mm})$ & & 50 & \\
\hline $\mathrm{D}_{(10)}, \mathrm{D}_{(30)}, \mathrm{D}_{(50)}$ & & $0.5,2.5,6.5,25$ & \\
\hline Passing \#200 (\%) & & 3.5 & \\
\hline $\mathrm{G}_{\mathrm{s}}$ (bulk specific gravity-oven dry) (ASTM C127) & 2.71 & 2.73 & 2.62 \\
\hline$\gamma_{\mathrm{d}(\max )}\left(\mathrm{kN} / \mathrm{m}^{3}\right)($ ASTM D1557, C-method) & 22.9 & 22.5 & 21.8 \\
\hline$\omega_{\text {opt }}(\%)$ & 5.33 & 6.67 & 6.1 \\
\hline $\mathrm{e}_{0}$ & 0.161 & 0.196 & 0.174 \\
\hline Is (ASTM D5731) & 3.07 & 2.83 & 2.85 \\
\hline Los Angeles abrasion for No. of rotations of 1000 (\%) (ASTM C131) & 40 & 43.9 & 44.9 \\
\hline
\end{tabular}

Table 2 Charestetistics of triaxial testing program according to ASTM D3999.

\begin{tabular}{llccc}
\hline Material symbol & \multicolumn{1}{c}{$\sigma_{3}^{\prime}(\mathbf{k P a})$} & $\begin{array}{c}\text { Number } \\
\text { of cycles }\end{array}$ & Frequency of loading (Hz) & Total No. \\
\hline S,SBU & $100,200,400,600,1000,1500$ & 40 & $0.1,0.2,0.5,1,2,5,10$ & $42+5^{*}$ \\
S.SBLII & $100,400,600,1000$ & 40 & $0.1,0.2,0.5,1,2,5,10$ & $28+3^{*}$ \\
S.SBLIV & $100,200,400,600,1000,1500$ & 40 & $0.5,0.2,0.5,1,2,5,7.5,10$ & $48+5^{*}$ \\
\hline
\end{tabular}

* $1 \mathrm{~Hz}$ repeated twice.

6.5 and $25 \mathrm{~mm}$, respectively. The passing percentage from sieve No. $4(4.75 \mathrm{~mm})$ and No. $200(0.075 \mathrm{~mm})$ is equal to $42 \%$ and $3.8 \%$, respectively. Maximum dry densities and optimum water contents were evaluated for samples according to the modified proctor (ASTM D1557). They were modified for oversize ( $20 \%$ higher than $19 \mathrm{~mm}$ ) percentage (ASTM 4718). Specific gravity (Gs) ranges from 2.62 to 2.73 , and minimum void ratio $\left(e_{0}\right)$ varies from 0.161 to 0.196 for the tested materials. Table 1 presents the main characteristics of tested materials, including size distribution, specific gravity, dry density, optimum water content, point load index and Los Angeles abrasion values.

Cyclic triaxial tests were carried out according to ASTM D3999 using large scale triaxial apparatus on cylindrical samples of $60 \mathrm{~cm}$ height and $30 \mathrm{~cm}$ diameter. A 2-mm membrane was used to encase the specimens and provide reliable protection against leakage. The specimens were prepared to the desired dry density by adding optimum moisture content, according to ASTM D698, in a split mold using a vibrator compactor operating at a frequency of 5060 cycles per seconds. Specimens were constituted in six equal layers. $\mathrm{CO}_{2}$ was passed through all specimens and then a vacuum was applied from the top for a period of up to 2 days. Saturation was achieved by allowing water to pass through the base of the triaxial cell, and by removing the air bubbles. To achieve full saturation (Skempton B value greater than 95 percent), back pressurization technique was used. The specimens were then subjected to the required consolidation pressures. The specimens were loaded under initial isotropic condition. Staged tests were performed to save cost and time. It is worth noting that the range of confining pressures in testing was chosen with respect to the stress levels in typical high CFRDs. Table 2 summarizes the characteristics of triaxial testing program including: confining pressure, loading frequency, number of loading cycles and number of samples prepared from each of three gravelly materials.
More details about specimen preparation, consolidation, testing procedure and the used equipment are presented in Aghaei Araei et al. (2010, 2012a, b, c).

\section{TEST RESULTS}

The shear modulus and the damping ratio versus shear strains, have been calculated based on the stressstrain hysteresis loop for the 1 to maximum $40^{\text {th }}$ cycles according to ASTM D3999. The relationship between $G$ and shear strain $(\gamma)$, shear stress $(\tau)$ and the relationships between stress-strain hysteresis loop for one cycle of loading and damping ratio is illustrated in Figure 1. The following relations would then be used for this purpose:

$$
\begin{aligned}
& E=2 \tau / \varepsilon_{1}, \gamma=(1+v) \varepsilon_{1}, \\
& G=E / 2(1+v)
\end{aligned}
$$

Where: $E=$ Young modulus, $\tau=$ shear stress, $G=$ shear modulus,$\varepsilon_{1}=$ axial strain, $\gamma=$ shear strain and $v=$ Poisson's ratio.

It's worth noting that in all calculations, Poisson's ratio, $\mathbf{v}$, is considered as 0.5 for saturated specimens because the test specimens are fully saturated and they have not been drained and are sheared under such conditions (Ishihara, 1996).

The $G-\gamma$ and $D-\gamma$ data points at the 10th cycle for gravelly materials at different conditions are shown in Figure 2. High sensitivity non-contact deformation transducers located on the opposite sides of the top plate were used to measure the average strain and eliminate the rotational component with the accuracy less than $0.001 \mathrm{~mm}$. The extrapolation method as used by Seed et al. (1998) was employed from $0.0001 \%$ strain to obtain $\mathrm{G}_{\max }$ for the materials. The $G-\gamma$ and $D-\gamma$ data are not significantly affected by the number of cycles due to excess pore water pressure (up to strain less than $0.1 \%$ ). Comprehensive details about specimens analyzed in this paper can be found in Aghaei Araei et al. (2010, 


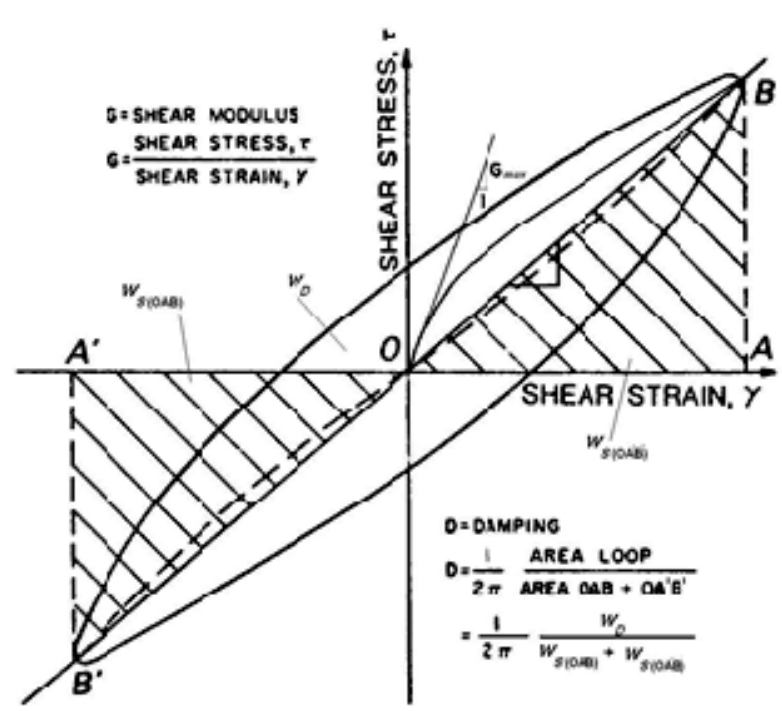

Fig. 1 Hysteresis stress-strain relation.

2011a, b, 2012 a, b, c). In Figure 2 the shear modulus and damping ratio are significantly affected by the confining pressure and loading frequency, respectively. Generally, as the confining pressure increases, the shear modulus increases and damping ratio decreases due to the densification of sample. Densification causes an increase in the relative density which further results in the increase of the shear modulus. The test results show that the shear modulus and specially damping ratios are significantly affected by the excitation frequency. It is worth mentioning that by increasing the loading frequency, damping ratio increases, even at medium and higher strain levels. It has been also observed and reported by previous researchers that, as the confining pressure increases, the shear modulus increases significantly and the damping ratio decreases (e.g. Iwasaki and Tatsuoka, 1977; Tatsuoka et al., 1978; Sitharam et al., 2004; Mohtar et al., 2013).

\section{PREDICTING NORMALIZED SHEAR MODULUS USING MODIFIED HYPERBOLIC MODEL}

The estimates of soil stiffness at any strain level are important for both earthquake and foundation
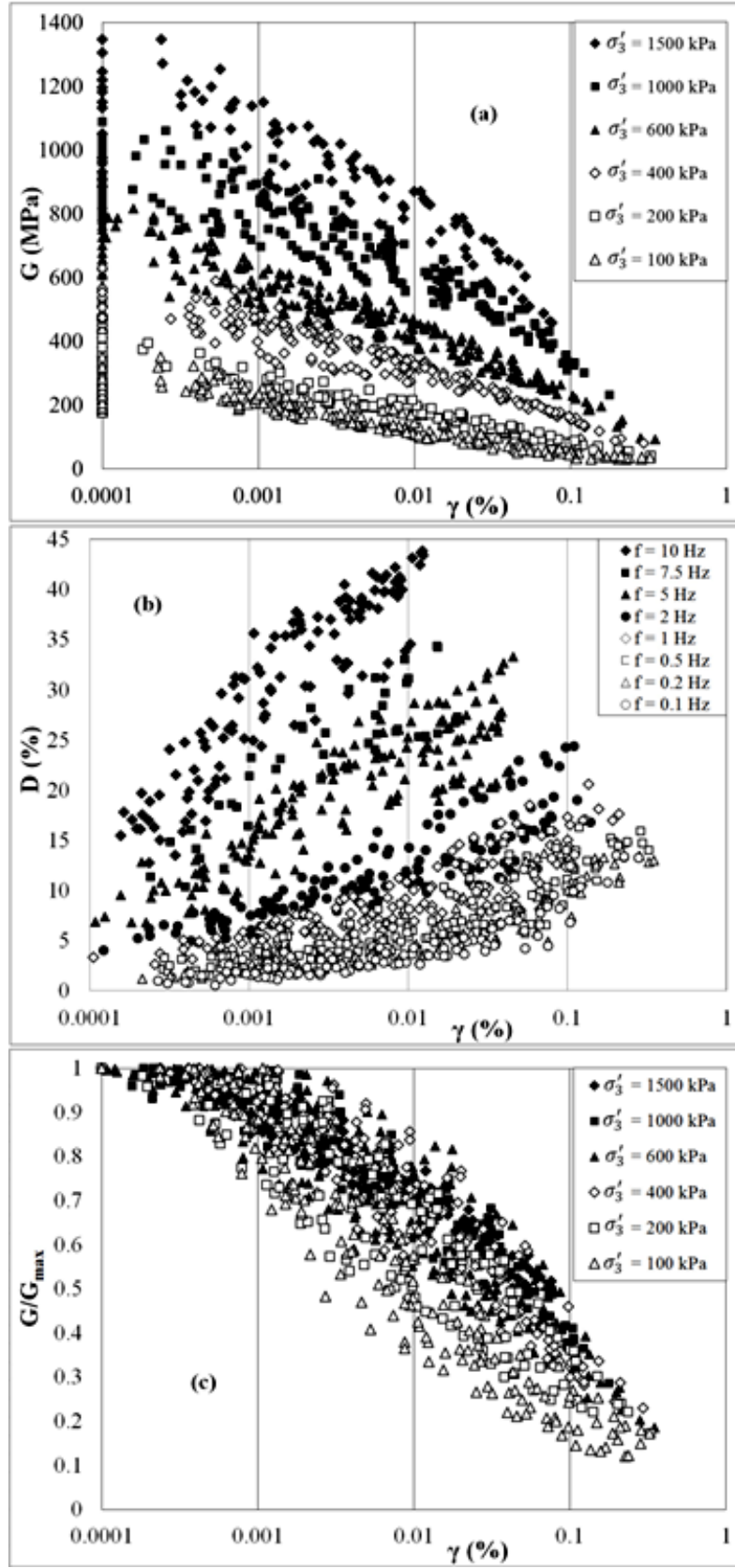

Fig. 2 Complied data points at $10^{\text {th }}$ cycle for tested gravelly materials under different conditions (a) $G-\gamma$, (b) $D-\gamma$ and (c) $G / G_{\max }-\gamma$.

engineering practices. A key parameter that must be well understood to make such predictions is the maximum shear modulus, $\mathrm{G}_{\max }$.

In this study, the modified hyperbolic model according to Eq. (2) was used to describe the nonlinear behavior of tested materials under cyclic loading:

$G / G_{\max }=\frac{1}{\beta+\delta\left(\gamma / \gamma_{r}\right)^{\alpha}}$

Where $\gamma_{r}$ is the reference strain (the shear strain corresponding to $\mathrm{G} / \mathrm{G}_{\max }=0.5$ ) and $\alpha$ is the second curvefitting variable called the curvature parameter. For the sake of presentation the value of $\alpha$ equal 0.8 was assumed. The coefficients $\beta$ and $\delta$ are determined through a multiple regression. The values of $G / G_{\max }$ ratio obtained from experiments and predictions for S.SBU materials in all investigated confining pressures and loading frequencies are shown in Figure 3. As seen, despite efforts made in the appropriate selection of coefficients in Eq. (2) the experimental and simulated (predicted) values have not been located properly around the tested-simulated line. The modified form of Eq. (2), by obtaining coefficients $\beta$ and $\delta$ has been presented as:

$G / G_{\max }=\frac{1}{\left(-0.0014 \sigma_{3}^{\prime 2}+0.0262 \sigma_{3}^{\prime}+0.9134\right)+\left(0.1548 \operatorname{Ln}\left(\sigma_{3}^{\prime}\right)+0.7842\right)\left(\gamma / \gamma_{r}\right)^{0.8}}$ 


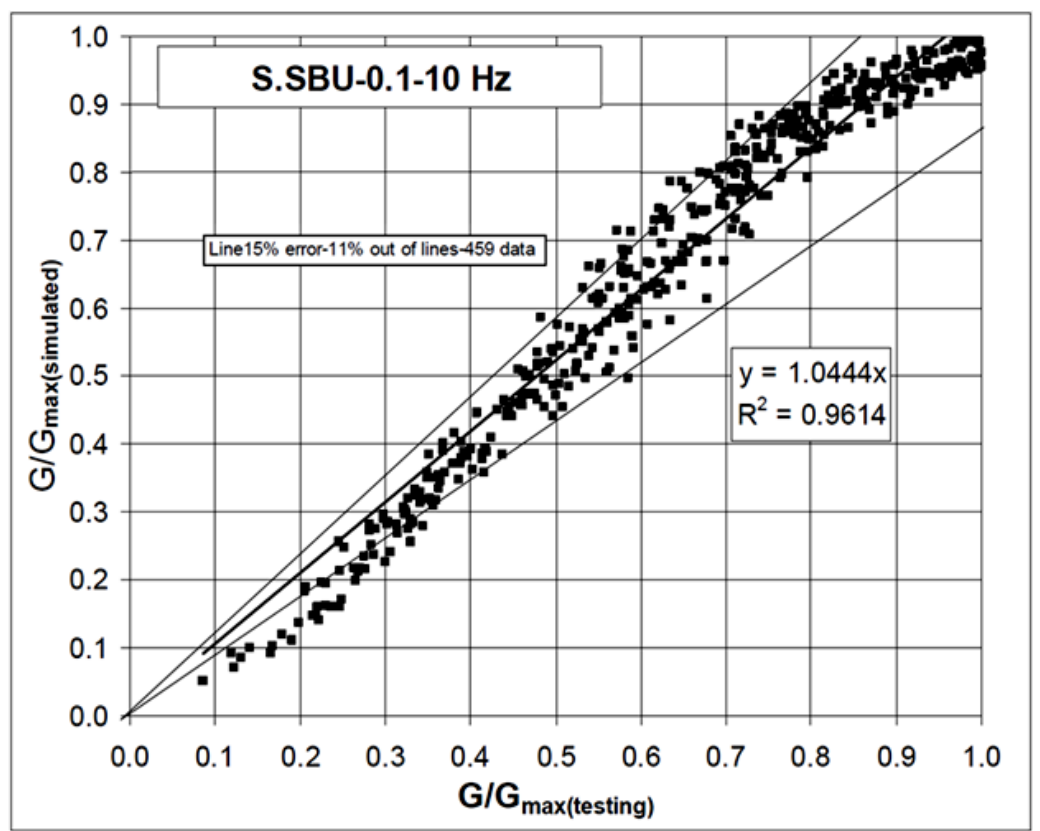

Fig. 3 The comparison of tested and simulated values of $G / G_{\max }$ using modified hyperbolic model.

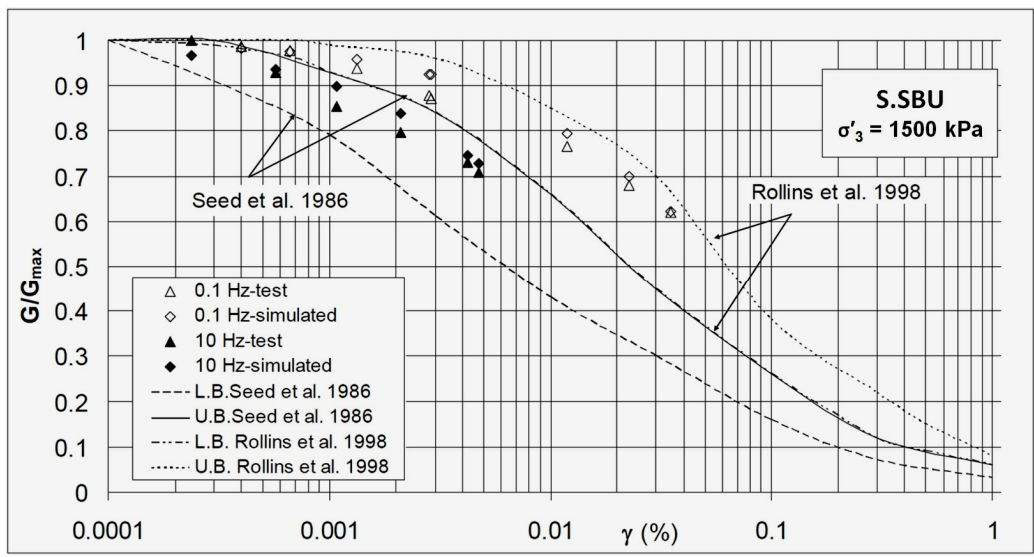

Fig. 4 The comparison of tested and simulated values of $G / G_{\max }$ using modified hyperbolic model for the S.SBU materials under confining pressure of $1500 \mathrm{kPa}$ and loading frequency of 0.1 and $10 \mathrm{~Hz}$.

Because of loading frequency and confining pressure effects, there were problems and limitations of choosing parameter $\gamma_{\mathrm{r}}$. In other words, in some cases, especially at high confining pressure and high loading frequency, it is difficult to reach $G / G_{\max }=0.5$ (Fig. 4). As a result, the parameter $\gamma_{r}$ is estimated by engineering judgment. Therefore, a different approach called nonlinear multiple regression method has been used in the shear modulus and damping ratio prediction of gravelly materials at different shear strain levels.

\section{PREDICTING DYNAMIC PROPERTIES OF REMODELED ROCKFILL MATERIALS USING NONLINEAR MULTIPLE REGRESSION}

The normalized shear modulus was predicted using the modified hyperbolic model in previous sections. The prediction results didn't have enough precise. Therefore, the ability of multiple regression method in predicting the dynamic properties of studied materials has been evaluated in this section.

\subsection{NORMALIZED SHEAR MODULUS RELATIONSHIPS}

As shown in Figure 5 the approach assumes a logarithmic form of the relationship between $G / G_{\max }$ and $\gamma\left(G / G_{\max }=a^{*} \operatorname{Ln}(\gamma)+b\right)$. The coefficients $\mathrm{a}$ and $\mathrm{b}$ are determined for different materials under various loading frequencies.

As shown in Figure 6, the relationship between the coefficient a and the confining pressure is assumed to have a power form with constants $\mathrm{c}$ and $\mathrm{d}$ $\left(-a=c^{*}\left(\sigma_{3}^{\prime}\right)^{d}\right)$. The relationship between the coefficient $b$ and confining pressure is assumed to a have a logarithmic form with constants e and $\mathrm{f}$ $\left(b=e^{*} \operatorname{Ln}\left(\sigma_{3}^{\prime}\right)+f\right)$. Figure 7 , for example presents 


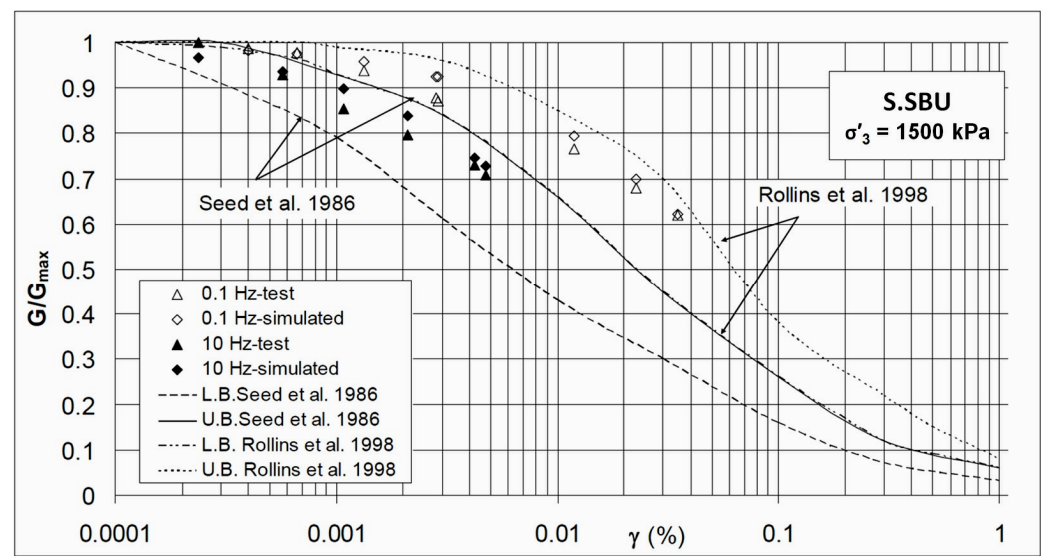

Fig. 5 The estimation of $G / G_{\max }$ values of the S.SBLIV under different confining pressure and loading frequency of $10 \mathrm{~Hz}$ using logarithmic form.

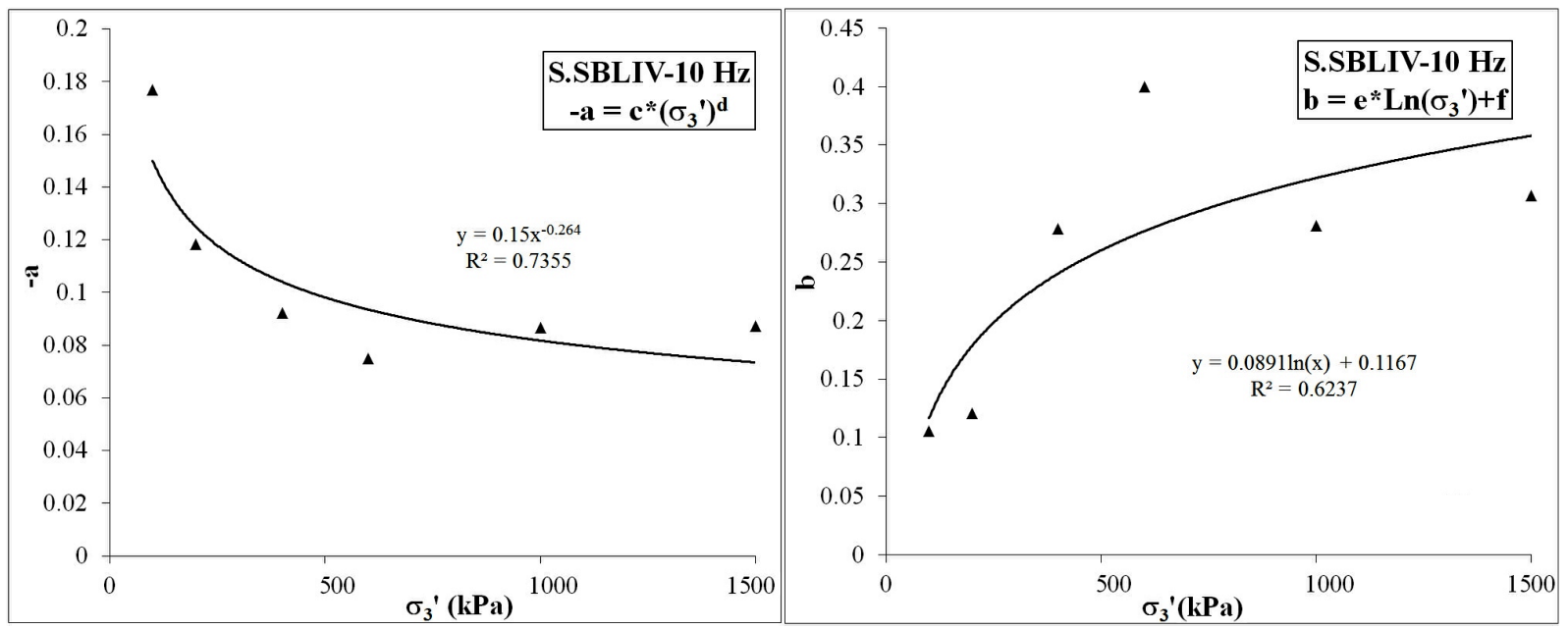

Fig. 6 The relationships of constants $\mathrm{c}, \mathrm{d}$, e and $\mathrm{f}$ and confining pressure for the S.SBLIV materials.

the relationship between constants c, d, e, f and frequency specified for S.SBLIV material. Eventually, the relationships among $G / G_{\max }$ and shear strain, confining pressure and loading frequency have been achieved by combination of all mentioned equations.

The comparison of the test results (references) and simulated $G / G_{\max }$ by considering strain and confining pressure for the S.SBLIV material at loading frequency of $10 \mathrm{~Hz}$ is shown in Figure 8. It is observed that the proposed relationship has a good performance in simulating the value of $G / G_{\max }$. Figure 9 compares the tested and simulated $G / G_{\max }$ by considering strain, confining pressure and loading frequency for the S.SBLII, S.SBU and S.SBLIV materials. According to Figure 9, data points lie around the tested-simulated line properly with a correlation coefficient $\left(\mathrm{R}^{2}\right)$ between 0.95 and 0.98 for all gravelly materials. Therefore, it can be interpreted that the values of $\mathrm{R}^{2}$ fully reflects the precision of the proposed predictive models.

The lines of $\pm 15 \%$ error for different materials are also shown in Figure 9 . The results indicate that only 459 data points (i.e. $3 \%$ data) are found out of the error lines for the S.SBU materials. The mentioned error values for the S.SBLII and S.SBLIV materials are 1 and $10 \%$, respectively. Therefore, it is concluded that the proposed relationship is suitable for simulating the values of $G / G_{\max }$. The following regression equations are suggested for prediction of $G / G_{\max }$ values for the S.SBU, S.SBLII and S.SBLIV materials:

$$
\begin{aligned}
& G / G_{\max }=(-0.001 f-0.1525) \sigma_{3}^{(-0.0032 f-0.196)} \operatorname{Ln}(\gamma)+(0.0062 f+0.1833) \operatorname{Ln}\left(\sigma_{3}^{\prime}\right)-0.0233 f-0.1735 \\
& G / G_{\max }=(-0.0027 f-0.1472) \sigma_{3}^{(-0.0102 f-0.1244)} \operatorname{Ln}(\gamma)+(0.0097 f+0.1269) \operatorname{Ln}\left(\sigma_{3}^{\prime}\right)-0.028 f-0.1021 \\
& G / G_{\max }=(-0.0003 f-0.1586) \sigma_{3}^{(-0.0266 f-0.1308)} \operatorname{Ln}(\gamma)+(0.0198 f+0.1088) \operatorname{Ln}\left(\sigma_{3}^{\prime}\right)-0.0197 f-0.0382
\end{aligned}
$$

Where, $\mathrm{f}$, loading frequency, $\sigma_{3}^{\prime}$, confining pressure and $\gamma$, is the shear strain. For instance Figure 10 compared the tested $G / G_{\max }$ data points and corresponding simulated values using Eq. (4) for the S.SBLII materials under 


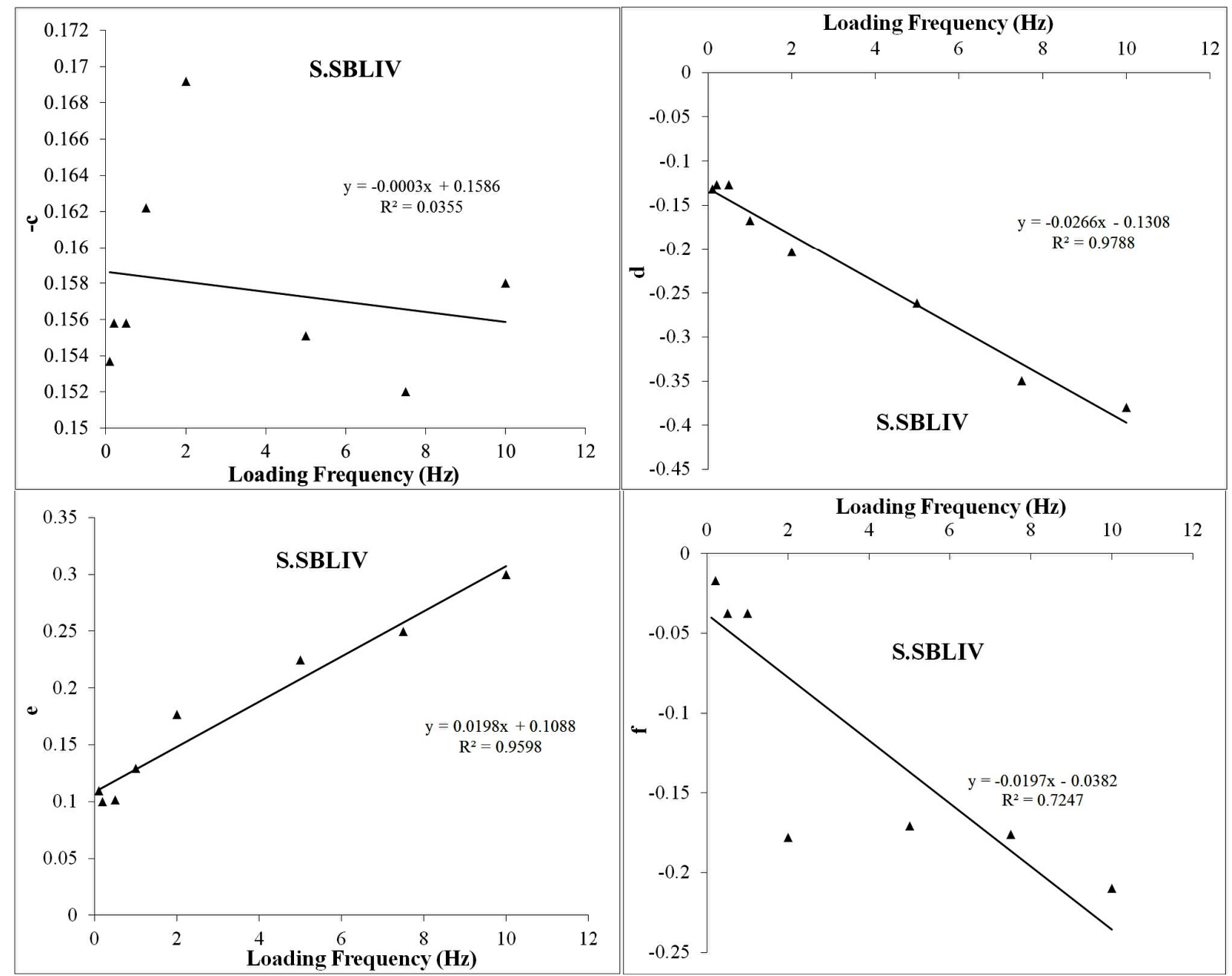

Fig. 7 The relationships of constants c, d, e and $\mathrm{f}$ and loading frequency for the S.SBLIV materials.

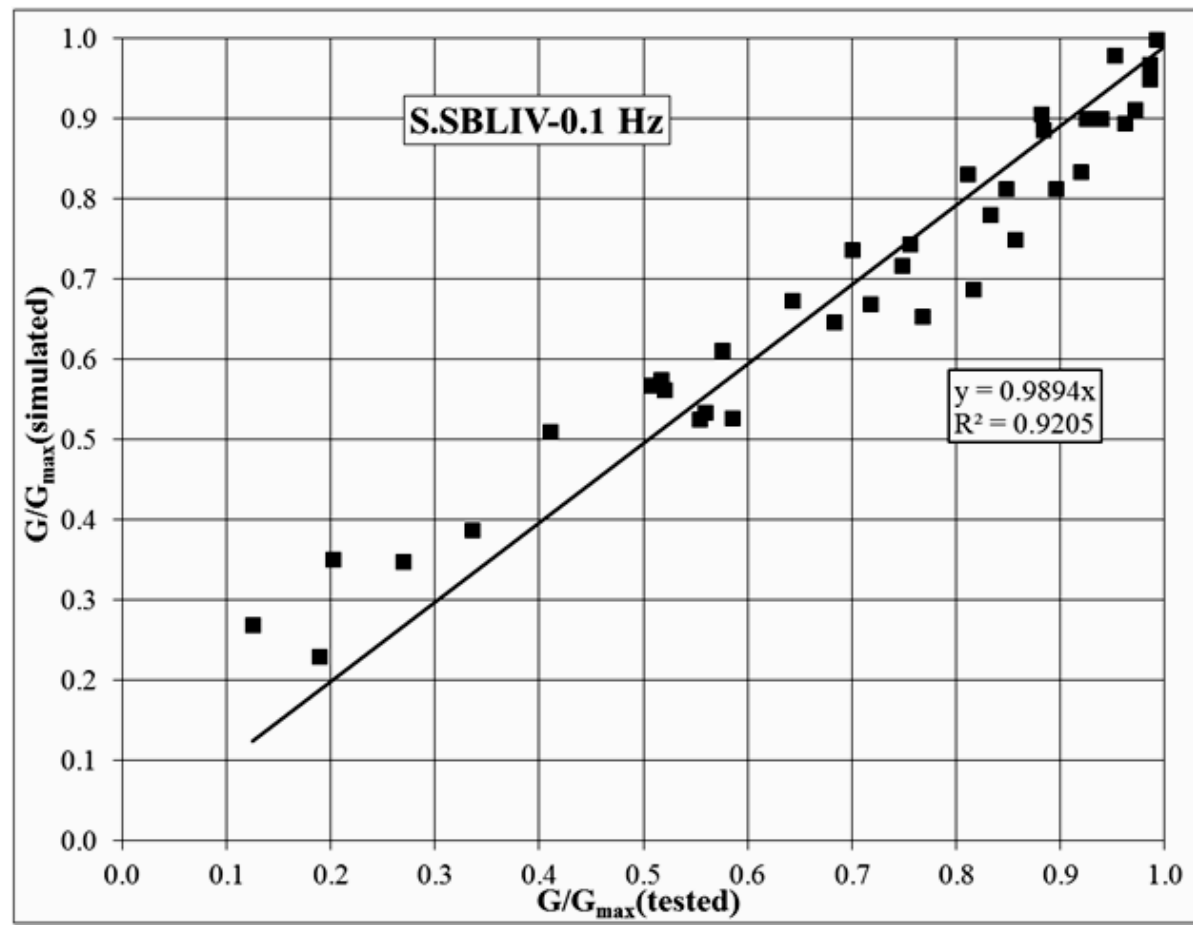

Fig. 8 The comparison of the tested and simulated $G / G_{\max }$ only by considering strain and confining pressure for the S.SBLIV materials at loading frequency of $10 \mathrm{~Hz}$. 

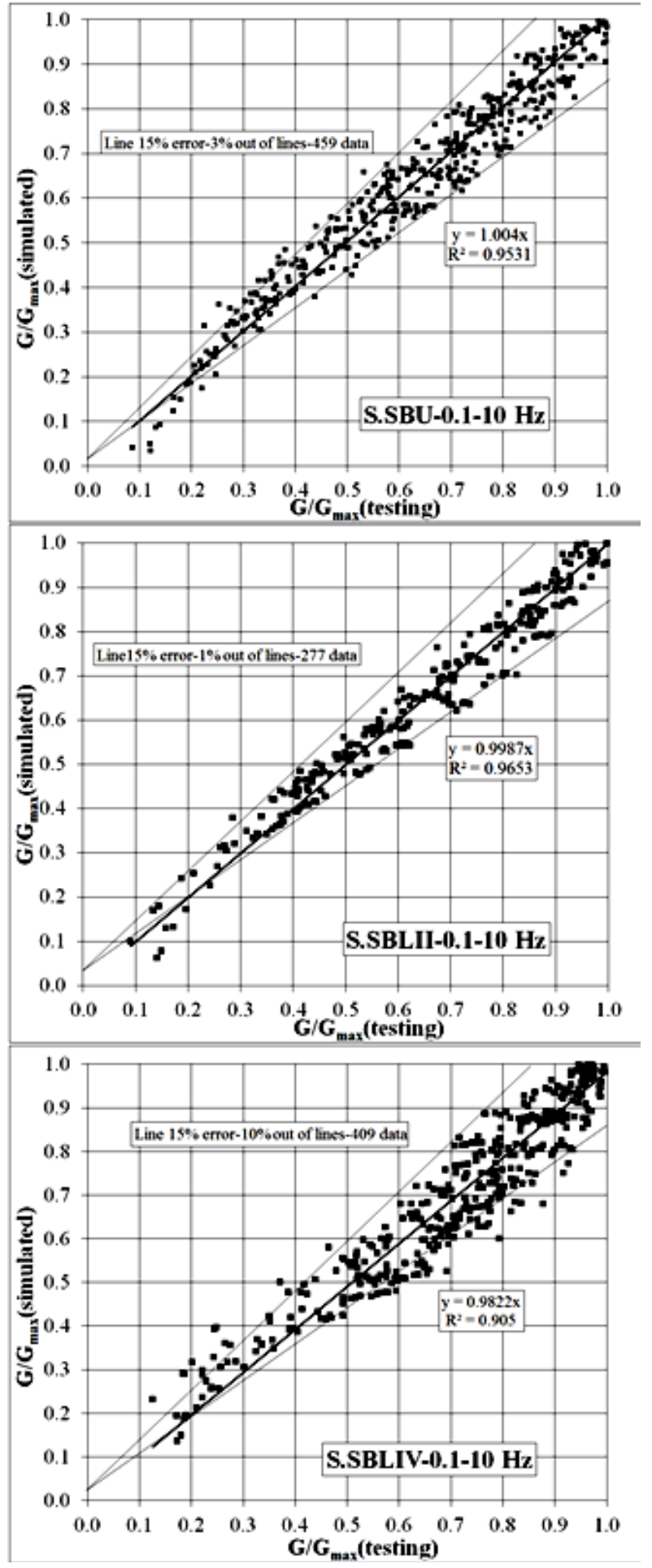

Fig. 9 The comparison of the tested and simulated $G / G_{\max }$ considering shear strain, confining pressure and loading frequency and the lines of $\pm 15 \%$ error for the S.SBU, S.SBLII and S.SBLIV material.

confining pressure $6 \mathrm{~kg} / \mathrm{cm}^{2}$ and loading frequency of 1 and $10 \mathrm{~Hz}$. It is observed that the results of the proposed equations are in a good agreement with those obtained by the dynamic triaxial tests.

\subsection{DAMPING RELATIONSHIPS}

The $D-\gamma$ curves obtained for gravelly materials in this study and those suggested by Seed et al. (1986) and Rollins et al. (1998) are remarkably different, especially at loading frequencies of 2 to $10 \mathrm{~Hz}$. Even at small strain under loading frequency of $1 \mathrm{~Hz}$, there is little difference between the test results and literature. For example, $D$ versus $G / G_{\max }$ curves for the S.SBLIV materials at different loading frequency presented in Figure 11. The average $D-G / G_{\max }$ curves proposed by Seed et al. (1986) and Rollins et al. (1986) for gravelly materials are also shown in Figure 11. The damping ratio increases by increasing the loading frequency at a constant $\mathrm{G} / \mathrm{G}_{0}$. In other words, $\mathrm{G} / \mathrm{G}_{0}$ is increased for a given damping ratio. Moreover, the damping ratio is always positive (greater than zero) at studied loading frequencies. The extreme reduction of the damping ratio values around $\mathrm{G} / \mathrm{G}_{0}=1$ at higher loading frequencies is another interesting point (see Fig. 11).

It is observed that when the results are presented in $D-G / G_{\max }$ form, the complex effects of confining pressure are eliminated and the interpretation of loading frequency effect could be facilitated. In this study, models based on the nonlinear multiple regression method have been adopted for the prediction of $D$ of the gravelly materials. For this purpose, three equations were used. Firstly, the relationship between $G / G_{\max }$ and $D$ under different confining pressures and a loading frequency is assumed to have a quadratic form $\left(D=A\left(G / G_{\max }\right)^{2}+B\left(G / G_{\max }\right)+C\right.$ ) (i.e. Fig. 12, for S.SBLIV materials under loading frequency of $10 \mathrm{~Hz}$ ). The coefficients $\mathrm{A}, \mathrm{B}$ and $\mathrm{C}$ are designated for different materials at different frequencies. The $\mathrm{G} / \mathrm{G}_{0}$ changing trend versus $\mathrm{D}$ at different confining pressure is not clear as illustrated in Figure 12. However, the damping ratio decreases by increasing the $\mathrm{G} / \mathrm{G}_{0}$ in all confining pressures. The greatest damping ratio value (approximately 42 percent) is also achieved at the lowest confining pressure. Then, the relationship between the coefficients $\mathrm{A}, \mathrm{B}, \mathrm{C}$ and confining pressure is assumed in a logarithmic form with pair of constants E-F, H-G and J-I, respectively (see Fig. 13 for S.SBLIV materials under the loading frequency of $10 \mathrm{~Hz}$ ).

Constants including E-F, H-G and J-I under different loading frequencies for coefficients A, B and $\mathrm{C}$ of S.SBU, S.SBLII and S. SBLIV materials are calculated based on regression analysis. Finally, the following regression equations are suggested for prediction of $D$ values for the S.SBLIV materials:

$$
\begin{aligned}
D= & \left(E \cdot \operatorname{Ln}\left(\sigma_{3}^{\prime}\right)+f\right)\left(c \cdot{\sigma_{3}^{\prime}}^{\prime} \cdot \operatorname{Ln}(\gamma)+e \cdot \operatorname{Ln}\left(\sigma_{3}^{\prime}\right)+f\right)^{2}+ \\
& +\left(G \cdot \operatorname{Ln}\left(\sigma_{3}^{\prime}\right)+H\right)\left(c \cdot \sigma_{3}^{\prime d} \cdot \operatorname{Ln}(\gamma)+e \cdot \operatorname{Ln}\left(\sigma_{3}^{\prime}\right)+f\right)+ \\
& +\left(I \cdot \operatorname{Ln}\left(\sigma_{3}^{\prime}\right)+J\right)
\end{aligned}
$$

For example, the experimental data and predicted values of $D$ using Eq. (5), (including parameters such as shear strain and confining 


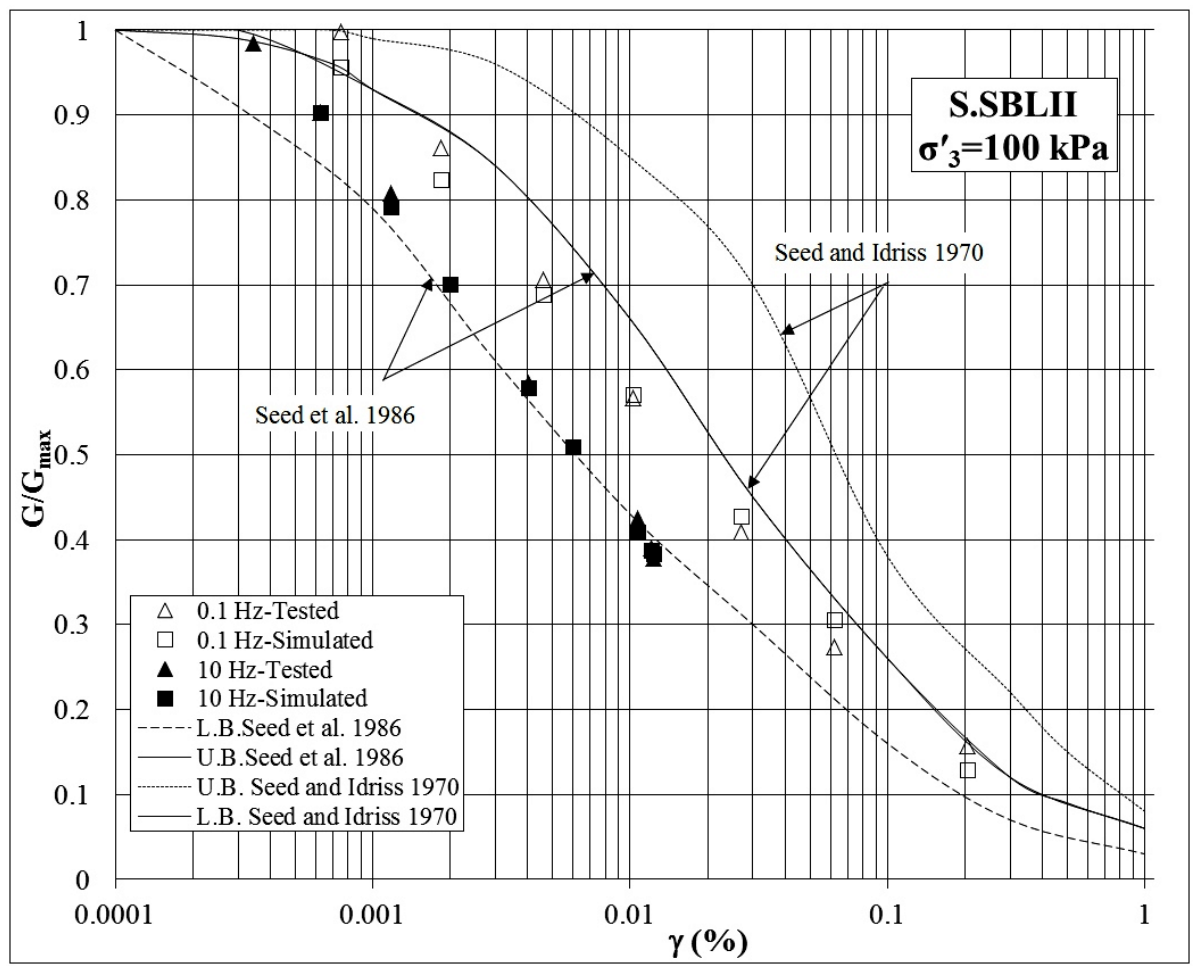

Fig. 10 The comparison of the tested and simulated $G / G_{\max }$ considering shear strain, confining pressure and loading frequency for the S. SBLII material.

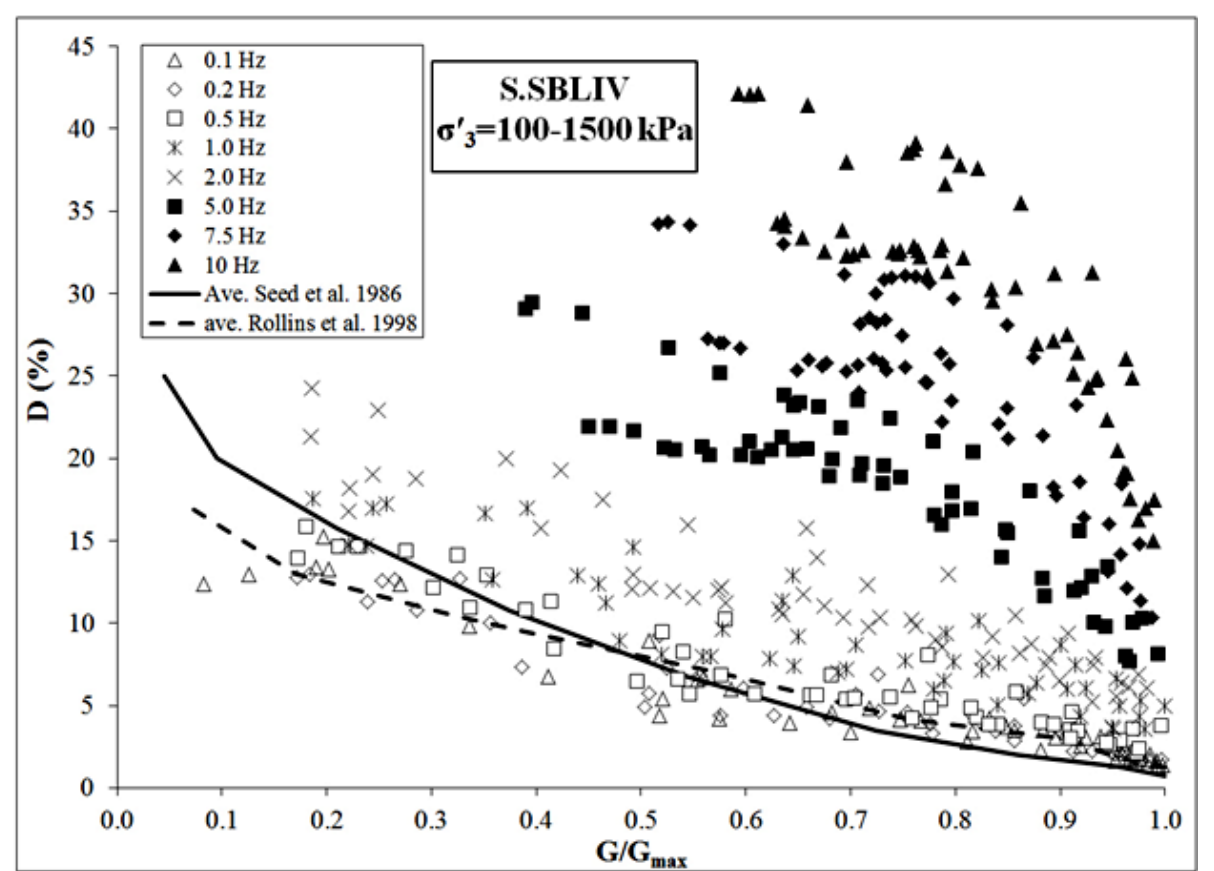

Fig. 11 The D versus $G / G_{\max }$ curves at different loading frequency for the S.SBLIV materials.

pressure) are presented in Figure 14. The error lines for the S.SBLIV materials are shown in Figure 14. It is observed that the suggested equation has an appropriate performance for the damping ratio prediction. Finally, the variations of constants E-F, G$\mathrm{H}$ and $\mathrm{J}-\mathrm{I}$ versus loading frequency for materials must be presented. For instance, the variations of constants E-F, G-H and J-I versus loading frequency for the S.SBLIV materials are shown in Figure 15.
Eventually, the relationship between $D$, shear strain, confining pressure and loading frequency is achieved by combination of all mentioned equations.

The comparison of experimental and simulated $D$ values by considering shear strain, confining pressure and loading frequency for the S.SBLU, S.SBLII and S.SBLIV materials is shown in Figure 16. According to Figure 16, data points lie around the tested-simulated line properly with a correlation 


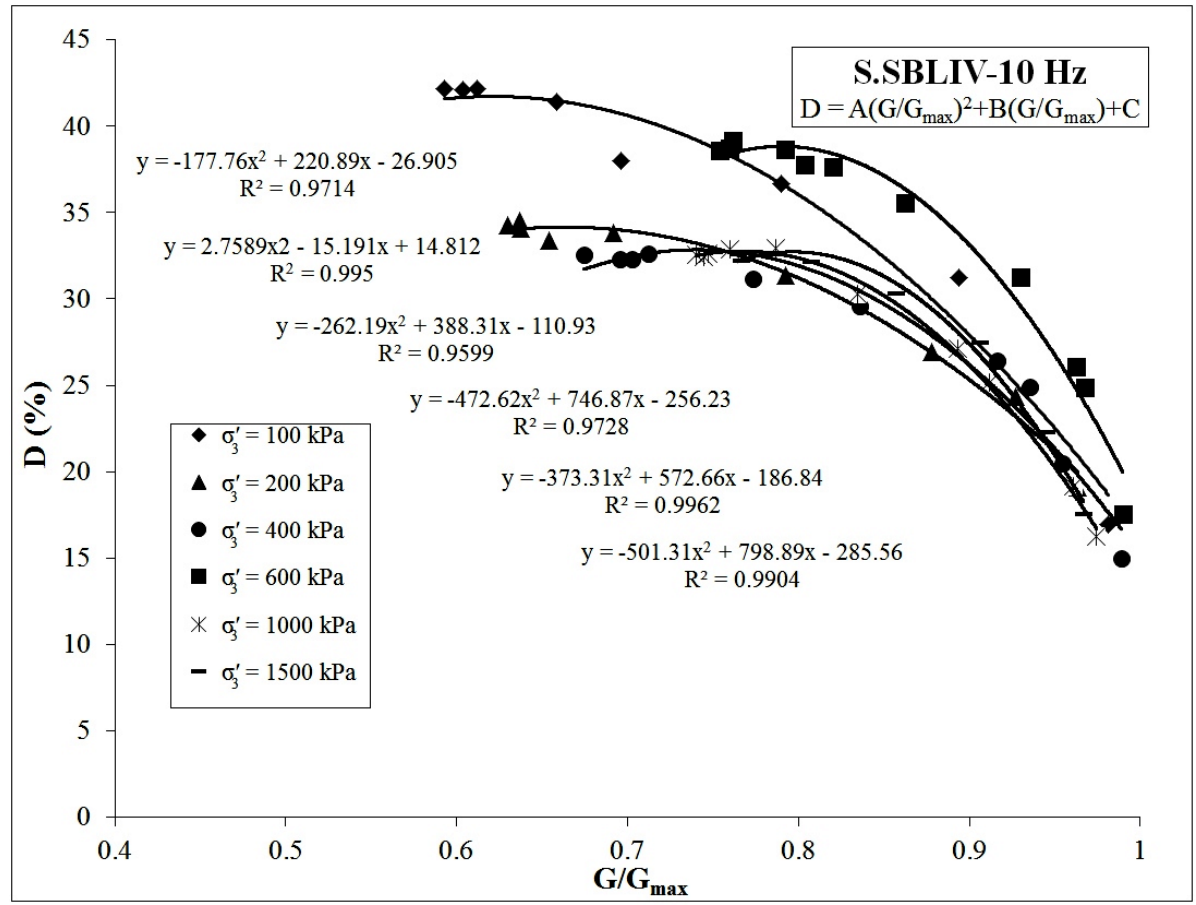

Fig. 12 The quadratic form of $D$ for the S.SBLIV materials at loading frequency of $10 \mathrm{~Hz}$.

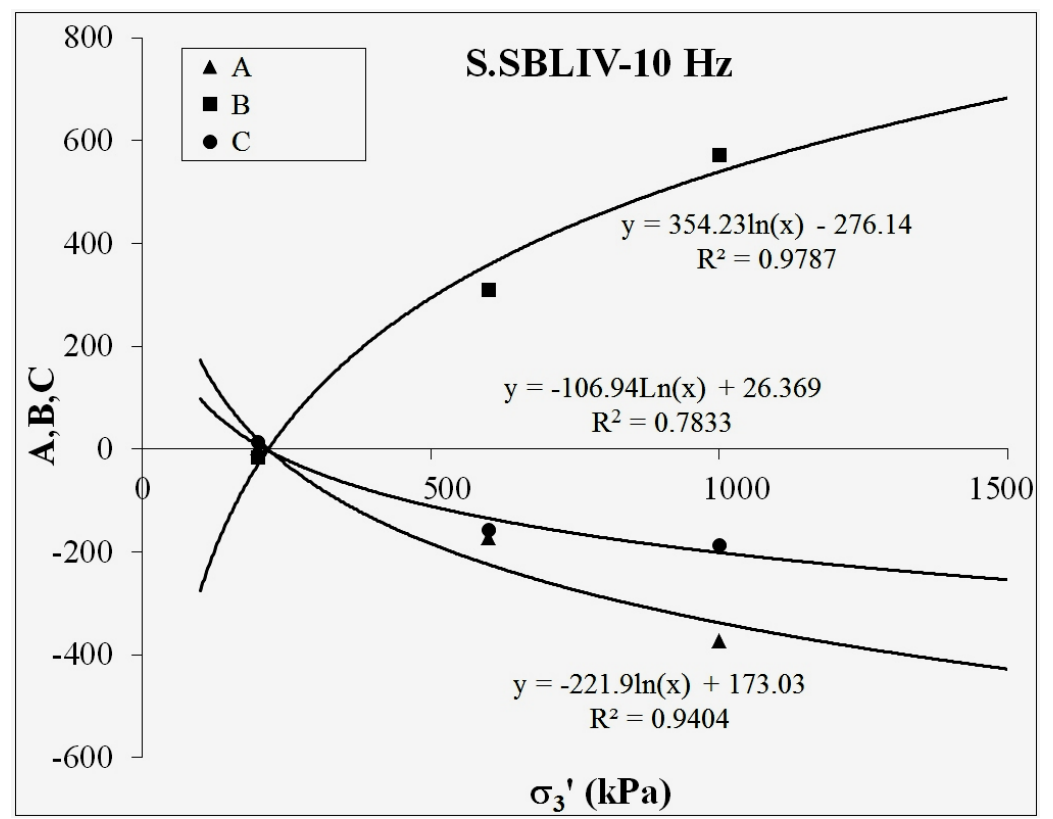

Fig. 13 The relationships of coefficients A, B, C and confining pressure for the S.SBLIV materials at loading frequency of $10 \mathrm{~Hz}$.

coefficient $\left(\mathrm{R}^{2}\right)$ between 0.93 and 0.98 for all gravelly materials. Therefore, it can be interpreted that the values of $\mathrm{R}^{2}$ fully reflect the complete agreement between simulated results and the measured $D$ values. The lines of $\pm 20 \%$ error for materials S.SBU are also shown in Figure 16. It is observed that only $10 \%$ of data points lies out of the errors lines. The mentioned error values for the S.SBLII and S.SBLIV materials are $2.5 \%$ and $13 \%$, respectively. Therefore, it is concluded that the proposed relationship is suitable for simulating the $D$ values under different conditions.
It should be noted that, part of the increase of damping ratio prediction error is related to the use of shear modulus formula. It is obvious that, if the real shear modulus values were available, the prediction error of the presented models would reduce remarkably.

\section{SUMMARY AND CONCLUSIONS}

This study presented predictive models to estimate the results of $G / G_{\max }-\gamma$ and $D$ behavior of compacted modeled rockfill materials. The facilitation 


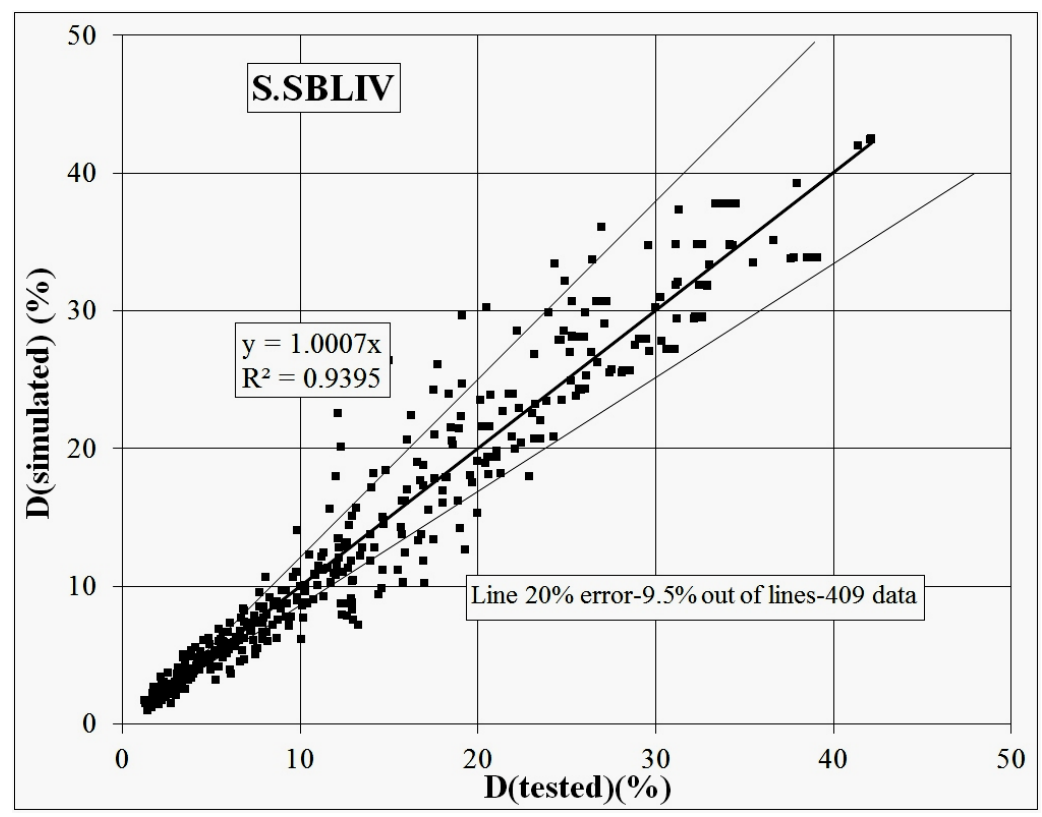

Fig. 14 The comparison of the tested and simulated $D$ considering shear strain and confining pressure for the S. SBLIV material at loading frequency of $10 \mathrm{~Hz}$.

of the shear modulus and damping curves usage in practice was the main purpose of presenting the mentioned models. The data related to the results of triaxial tests conducted on 131 large-scale cylindrical specimens with a diameter of 30 and $60 \mathrm{~cm}$ in height under different confining pressures and loading frequencies were used in the development of the models. In preliminary stage, a hyperbolic model was used and next the models, based on nonlinear multiple regression, were presented. The most important factors considered in the modeling of the test results include: the shear strain amplitude, confining pressure and loading frequency. The proposed models predictions are in a good agreement with the experimental data. The principle findings can be summarized as follows:

- Despite efforts made in appropriate selection of coefficients in the modified hyperbolic model, the experimental and simulated values have not been located around the tested-simulated line properly. The other problem was the determination of the parameter $\gamma_{r}$, because of loading frequency and confining pressure effects. In other words, in some cases, especially at high confining pressure and high loading frequency conditions, the tests data at shear strain about $G / G_{\max }=0.5$ and less are not available, and the parameter $\gamma_{r}$ needs to be estimated by engineering judgment. This increases the predictions errors.

- The development of models based on nonlinear multiple regression leads to more accurate $G / G_{\max }$ results with consideration of strain, confining pressure and loading frequency for the studied materials.. The data points lie around the testedsimulated line properly with a correlation coefficient $\left(\mathrm{R}^{2}\right)$ between 0.95 and 0.98 for all gravelly materials. The lines of $\pm 15 \%$ error for the S.SBU, S.SBLII and S.SBLIV materials show that, only $3 \%, 1 \%$ and $10 \%$ of data points, respectively, lie out of the errors lines.

- Predictions of the damping ratio of gravelly materials using nonlinear multiple regression models were successful. The data points lie around the tested-simulated line properly with a correlation coefficient $\left(\mathrm{R}^{2}\right)$ between 0.93 and 0.98 for all gravelly materials. The lines of $\pm 20 \%$ error for the S.SBU, S.SBLII and S.SBLIV materials show that, only $10 \%, 2.5 \%$ and $13 \%$ of data points, respectively, lie out of the errors lines.

- The interpretation of loading frequency effect could be facilitated by eliminating the complex effects of confining pressure and presenting the results in the form of $D-G / G_{\max }$ curves. Also, if the real shear modulus values were available, the prediction error of the presented models would reduce remarkably.

- The comparison of prediction results shows that the nonlinear multiple regression method has appeared very effective in modeling complex dynamic properties of gravelly soils studied in this paper, such as the shear modulus and damping ratio, and delivers more precise results than classical method such as the modified hyperbolic models.

\section{ACKNOWLEDGEMENTS}

The authors are grateful to the Department of Geotechnical Engineering, BHRC for conducting the tests and for financial support, and to the Ministry of Energy, as the project's client for providing data for this research. 


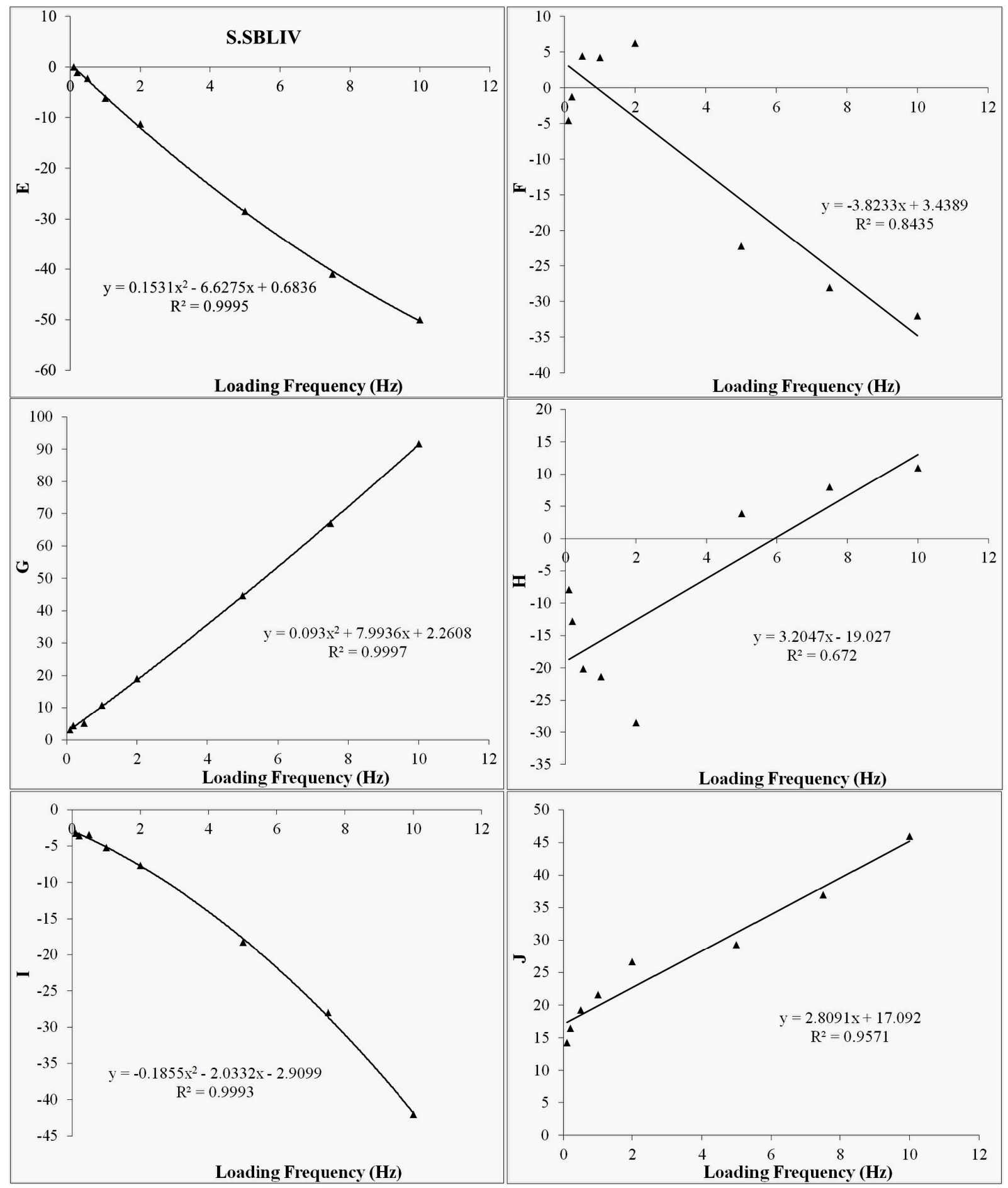

Fig. 15 The variations of constants E-F, G-H and J-I versus loading frequency for the S.SBLIV materials.

\section{NOTATION}

The following symbols are used in this paper: CFRDs: Concrete Faced Rockfill Dams

$G$ : $\quad$ Shear modulus

$G_{0}: \quad$ Maximum value of shear modulus

$\gamma_{r}: \quad$ Reference shear strain at $\mathrm{G} / \mathrm{G}_{0}=0.5$

$D: \quad$ Damping ratio

$\gamma: \quad$ Shear strain $\sigma_{3}^{\prime}$ : Effective minor principal stress, Effective confining pressure

$\sigma_{m}^{\prime}=\left(\sigma_{1}^{\prime}+2 \sigma_{3}^{\prime}\right) / 3:$ Mean effective stress

$P I$ : $\quad$ Plasticity index

$G_{\max }: \quad$ Maximum value of shear modulus

kPa: kilo Pascal

$\mathrm{Hz}$ : Hertz 

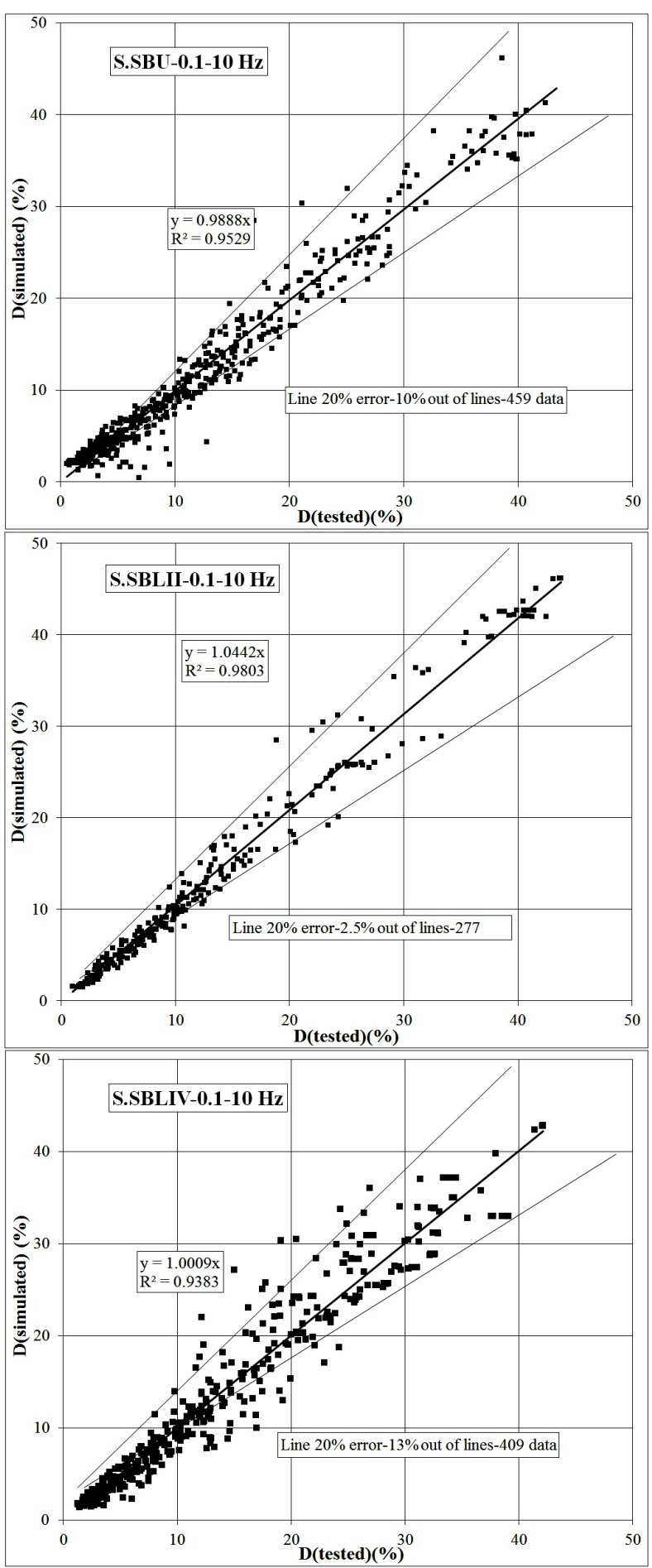

Fig. 16 The comparison of the tested and simulated $D$ considering shear strain, confining pressure and loading frequency and the lines of $\pm 20 \%$ error for the S.SBU, S.SBLII and S.SBLIV materials.

$D(10), D(30), D(50), D(85)(\mathrm{mm})$ : Particle size $(\mathrm{mm})$ corresponding to $10,30,50$ and 85 passing percentage, respectively

$G_{s}: \quad$ Specific gravity

$e_{0}$ : Void ratio according to modified proctor compaction

$\gamma_{d}: \quad$ Dry density $\omega_{\text {opt }}: \quad$ Optimum water content

$I_{s}: \quad$ Point load index

$v: \quad$ Poisson's ratio

$E$ : $\quad$ Young modulus

$\varepsilon_{1}=\quad$ axial strain

L.B. : Lower Bound

U.B. : Upper Bound

\section{REFERENCES}

ASTM D3999: 2006, Standard test methods for the determination of the modulus and damping properties of soils using the cyclic triaxial apparatus.

ASTM 1557: 2007, Standard test methods for laboratory compaction characteristics of soils using modified effort.

ASTM D4718: 2003, Practice for correction of unit weight and water content for soils containing oversize particles.

Aggur, M. and Zhang, J.: 2006, Degradation of sands due to combined sinusoidal loading. Geotech. Geoenviron. Eng., ASCE, 132 (12), 1628-1632.

DOI: 10.1061/(ASCE)1090-0241(2006)132:12(1628)

Aghaei Araei, A., Razeghi, H.R, Tabatabaei, S.H. and Ghalandarzadeh, A.: 2009, Evaluation of frequency content on properties of gravelly soils. Research project. No. 1-1775-2008. BHRC. Iran.

Aghaei Araei, A., Razeghi, H.R., Tabatabaei, S.H. and Ghalandarzadeh, A.: 2010, Dynamic properties of gravelly materials. ScientiaIranica, Trans. A, Civil Eng., 17(4), 245-261.

Aghaei Araei, A., Tabatabaei, S.H. and Ghalandarzadeh, A.: 2011a, Assessment of shear modulus and damping ratio of gravelly soils. BHRC Publication, No. R-548, BHRC, Iran.

Aghaei Araei, A., Razeghi, H.R., Tabatabaei, S.H. and Ghalandarzadeh, A.: 2011b, Evaluation of frequency content on properties of gravelly soils. BHRC Publication, No. R-630, BHRC, Iran.

Aghaei Araei, A., Razeghi, H.R., Tabatabaei, S.H. and Ghalandarzadeh, A.: 2012a, Loading frequency effect on stiffness, damping and cyclic strength of modeled rockfill materials. Soil Dynamics and Earthquake Engineering, Elsevier, 33(1), 1-18.

DOI:10.1016/j.soildyn.2011.05.009

Aghaei Araei, A., Razeghi, H.R., Ghalandarzadeh, A. and Tabatabaei, S.H.: 2012b, Effects of loading rate and initial stress state on stress-strain behavior of rockfill materials under monotonic and cyclic loading conditions. ScientiaIranica, Trans. A, Civil Eng., 19(5), 1220-1235. DOI:10.1016/j.scient.2012.08.002

AghaeiAraei, A., Tabatabaei, S.H. and Razeghi, H.R.: 2012c, Cyclic and post-cyclic monotonic behavior of crushed conglomerated rockfill material under dry and saturated conditions. ScientiaIranica, 19(1), 64-76. DOI:10.1016/j.scient.2011.12.001

Akbulut, S., Hasiloglu, A.S., and Pamukcu, S.: 2004, Data generation for shear modulus and damping ratio in reinforced sands using adaptive neuro-fuzzy inference system. Journal of Soil Dynamic and Earthquake Engineering, 24, 805-814. DOI:10.1016/j.soildyn.2004.04.006

Anderson, D.: 1974, Dynamic modulus of cohesive soils. $\mathrm{Ph}$.D. dissertation. University of Michigan, USA.

Drendeli, M.: 1997, Dynamic properties of soils subjected to 1994 Northridge Earthquake, M.S. dissertation. University of Texas at Austin, USA. 
Drendeli, M.: 2001, Development of a new family of normalized modulus reduction and material damping curves. Ph.D. dissertation, University of Texas at Austin, USA.

Hardcastle, J.H. and Sharma, S.: 1998, Shear modulus and damping of unsaturated loess. Geotechnical Earthquake Engineering and Soil Dynamics III, ASCE Geotechnical Special Publication 75, 178-188.

Hardin, B. and Drenvich, V.: 1972a, Shear modulus and damping in soils: Measurement and parameter effects. J. Soil Mech. Found., ASCE, 18 (SM6), 603-642.

Hardin, B. and Drenvich, V.: 1972b, Shear modulus and damping in soils: Design equations and curves. J. Soil Mech. Found., ASCE, 98 (SM7), 667-692.

Hudson, M., Idriss, I., and Beikae, M.: 1994, User's manual for QUAD4M: a computer program to evaluate the seismic response of soil structures using finite element procedures and incorporating a compliant base. University of California, Davis, USA.

Idriss, I., Lysmer, J., Hwang, R., and Seed, H.: 1973, QUAD4: A computer program for evaluating the seismic response of soil structures by variable damping finite element procedures. EERC Report, 7316. University of California, Berkeley, USA.

Idriss, I.M., Dobry, R. and Singh, R.D.: 1978, Nonlinear behavior of soft clays during cyclic loading. Journal of the Geotechnical Engineering Division, ASCE, 104(12), 1427-1447.

Ishihara, K.G.: 1996, Soil behavior in earthquake engineering. Oxford, Clarendon Press.

Iwasaki, T. and Tatsuoka, F.: 1977, Effects of grain size and grading on dynamic shear moduli of sands. Soils and Foundations, 17, No. 3, 19-35.

Jafarian, Y., Haddad, A. and Javadian, H.: 2014, Predictive model for normalized shear modulus of cohesive soils, Acta Geodyn. Geomater., 11, No. 1 (173), 89-100. DOI: 10.13168/AGG.2013.0057

Khouri, N.: 1984, Dynamic properties of soils. M.S. dissertation. Department of Civil Engineering, Syracuse University.

Kokusho, T.: 1980, Cyclic triaxial test of dynamic s range. Soils and Foundations, 20(2), 45-60.

Kokusho, T., Yoshida, Y. and Esashi, Y.: 1982, Dynamic properties of soft clay for wide strain range. Soils and Foundations, 22(4), 1-18.

Meng, F.Y.: 2003, Dynamic properties of sandy and gravelly soils. Ph.D. dissertation, University of Texas, Austin, USA.

Mohtar, C.S.E., Denevich, V.P., Santagata, M. and Bobet, A.: 2013, Combined resonant column and cyclic triaxial tests for measuring undrained shear modulus reduction of sand with plastic fines. Geotechnical Testing Journal, ASTM, 36(4), 1-9. DOI: $10.1520 /$ GTJ20120129

Okur, D. and Ansal, A.: 2007, Stiffness degradation of natural fine grained soils during cyclic loading. Soil Dyn. Earthquake Eng., 27, 843-854. DOI:10.1016/j.soildyn.2007.01.005
Rollins, K.M., Evans, M.D., Diehl, N.B. and Daily, W.D.: 1998, Shear modulus and damping relationships for gravels. Journal of Geotechnical and Geoenvironmental Engineering, ASCE, 124(5), 398-405. DOI: 10.1061/(ASCE)1090-0241(1998)124:5(396)

Shenabel, P., Lysmer, J., and Seed, H.: 1972, SHAKE: A computer program for earthquake response analysis of horizontally layered site. Berkeley, University of California, USA.

Seed, H.B., and Idriss, I.M.: 1970, Soil moduli and damping factors for dynamic response analysis. Report EERC, 70-10, Berkeley, CA, USA: University of California.

Seed, H.B., Wong, R.T, Idriss, I.M. and Tokimatsu, K.: 1986, Moduli and damping factors for dynamic analysis of cohesionless soils. Journal of Geotechnical Engineering, 112(11), 1016-1032. DOI: 10.1061/(ASCE)0733-9410(1986)112:11(1016)

Sitharam, T.G., GovindaRaju, L. and Murthy, B.R.S.: 2004, Evaluation of liquefaction potential and dynamic properties of silty sand using cyclic triaxial testing. Geotechnical Testing Journal, 27, No. 5, Paper ID GTJ11894. DOI: 10.1520/GTJ11894

Stokoe, K., Drendeli, M., Gilbert, R., Meng, F.Y. and Choi, W.K.: 2004, Development of a new family of normalized modulus reduction and material damping curves. In: Proceedings of the NSF/PEER International Workshop on Uncertainties in Nonlinear Soil Properties and their Impact on Modeling Dynamic Soil Response, University of California at Berkeley, Berkeley, California, USA.

Sun, J., Golesorkhi, R. and Seed, H.: 1988, Dynamic moduli and damping ratios of cohesive soils. Report, UCB/EERC-88/15.University of California, Berkeley, USA.

Tatsuoka, F., Iwasaki, T. and Takagi, Y.: 1978, Hysteretic damping of sands under cyclic loading and its relation to shear modulus. Soils and Foundations, 18(2), 2530. DOI: $10.3208 /$ sandf1972.18.2 25

Teachavorasinskun, S., Thongchim, P. and Lukkunaprasit, P.: 2001, Shear modulus and damping ratio of a clay during undrained cyclic loading. Géotechnique, 51(5), 467-470. DOI: 10.1680/geot.51.5.467.39968

Vardanega, P.J. and Bolton, M.D.: 2013, Stiffness of clays and silts: Normalizing shear modulus and shear strain. Journal of Geotechnical and Geoenvironmental Engineering, 139, 1575-1589. DOI: 10.1061/(ASCE)GT.1943-5606.0000887

Vucetic, M. and Dobry, R.: 1991, Effect of soil plasticity on cyclic response. J. Geotech. Eng., 117 (1), 89-107. DOI: $10.1061 /(\mathrm{ASCE}) 0733-9410$

Wilson, J.M.R.: 1988, A theoretical and experimental investigation into the behaviour of soils. $\mathrm{PhD}$ thesis, University of Cambridge, UK.

Zhang, J., Andrus, R. and Juang, C.: 2005, Normalized shear modulus and material damping ratio relationships. J. Geotech. Geoenviron. Eng., ASCE, 131, 453-464. DOI: 10.1016/j.sandf.2013.10.007 